Artigo original

Hegemonia - Revista Eletrônica de Relações Internacionais do Centro Universitário Unieuro

ISSN: 1809-1261

UNIEURO, Brasília, número 20, Janeiro-Junho de 2017, pp. 27-49.

Recebido em: 4/10/2016

Avaliado em: 2/11/2016

Aprovado em: 3/12/2016

\title{
Infancias: perspectivas para una nueva racionalidad ambiental
}

\author{
Celeste Skewes Guerra ${ }^{1}$ e Andrea Ciacchi ${ }^{2}$
}

Resumen: En este trabajo se reflexiona acerca del desarrollo que ha tenido la visión de naturaleza en la modernidad y sus consecuencias en América Latina. El análisis pone en relieve las carencias de una visión de naturaleza basada en la racionalidad moderna occidental, que entre otras problemáticas, ha provocado la proliferación de conflictos socio-ambientales en la región. Esta racionalidad instrumental, que ha sido hegemónica en un contexto global, excluye los saberes de otros actores, entre ellos niños y niñas. Es por ello que aquí se propone indagar acerca de cómo las y los niños pueden ser tomados en consideración, por su visión propia y diferenciada del mundo, comprendiéndoles como sujetos relevantes en la estructura social, y, por ende, partícipes en su transformación. De esta manera, se plantea incluir las perspectivas infantiles acerca de la naturaleza en la búsqueda de una nueva racionalidad ambiental.

Palabras claves: infancia, racionalidad ambiental, conflicto socio-ambiental, América Latina.

Resumo: Este trabalho se reflexiona acerca do desenvolvimento da visão da natureza no contexto da modernidade e as suas consequências na América Latina. Essa analise releva as carências de uma visão de natureza baseada na racionalidade moderna ocidental, que entre outras problemáticas, tem provocado a proliferação dos conflitos socioambientais na região. Esta racionalidade instrumental, que tem sido hegemónica num contexto global, exclui os saberes de outros atores, entre eles crianças. $\mathrm{E}$ por isto que aqui se propõe indagar acerca de como as crianças podem ser tomados em consideração, por sua visão própria e diferenciada do mundo, compreendendo-os como sujeitos relevantes na estrutura social, e, por tanto, partícipes da sua transformação. De essa maneira, se propõe incluir as perspectivas infantis, na sua relação com a natureza em busca de uma nova racionalidade ambiental.

Palavras chaves: infância; racionalidade ambiental; conflito socioambiental; América Latina

Abstract: This paper reviews the development of the modern vision of nature and its consequences in Latin America. The analysis highlights the deficiency in a vision of nature based on modern

\footnotetext{
${ }^{1}$ Estudiante de programa de pos graduación Interdisciplinar en Estudios Latinoamericanos, Universidad Federal de la Integración Latinoamericana -UNILA- Foz do Iguaçu, Brasil. Correo electrónico: celesteskewes@gmail.com.

${ }^{2}$ Docente no Programa de Pós Graduação Interdisciplinar em Estudos Latino-Americanos (IELA) e do Programa de Pós-Graduação em Literatura Comparada, ambos da Universidade Federal da Integração Latino Americana (UNILA).
} 
Artigo original

Hegemonia - Revista Eletrônica de Relações Internacionais do Centro Universitário Unieuro

ISSN: $1809-1261$

UNIEURO, Brasília, número 20, Janeiro-Junho de 2017, pp. 27-49.

occidental rationality that, between other things, has caused the proliferation of socio-environmental conflicts in the region. This instrumental rationality, witch has been hegemonic in a global context, excludes knowledge of other actors, among witch we find children. That being so, this article proposes to enquire into how children can be taken in consideration, for their own and differential visions of the word, understanding them as agents in the social structure and therefor participants in its transformation. Thus, this proposal considers important to include children's perspective about nature in the search of a new environmental rationality.

Key words: childhood, environmental rationality; socio-environmental conflicts; Latin America.

\section{INTRODUCCIÓN}

En la discusión sobre la racionalidad moderna y su abordaje acerca de la naturaleza, la propuesta del presente trabajo busca comenzar una reflexión teórica acerca de las posibilidades que tiene la inclusión de las perspectivas de niños y niñas en la búsqueda una nueva racionalidad ambiental. Con ello se espera contribuir a emprender un camino inclusivo y emancipador de una ciudadanía para la transformación del complejo escenario socio-ambiental que actualmente enfrenta América Latina.

La perspectiva del presente trabajo busca ahondar en la posibilidad de considerar las formas de ver y vivir la naturaleza de sujetos que habitualmente no son considerados como agentes con potencial de transformación social, como es el caso de las y los niños. Se destaca de esta manera la relevancia de conocer la visión de los infantes con el objetivo de conocer miradas que contribuyan a concebir el mundo fuera de los límites de la racionalidad moderna y adultocéntrica. Es por esto que se cree urgente poner en relieve nuevas miradas para visualizar salidas a la crisis provocada por la acción humana y guiada por la razón moderna.

Para dar cuenta de esta propuesta se abordan los siguientes ámbitos conceptuales: la mirada histórica de la comprensión moderna de la naturaleza; desde una perspectiva geopolítica: los conflictos socio-ambientales en la modernidad; la crisis de la racionalidad moderna y la búsqueda de una nueva racionalidad ambiental; y, finalmente, desde la perspectiva teórica de los estudios de infancia, se aborda la posibilidad de considerar a las y los niños como agentes con poder de transformación social. 
Artigo original

Hegemonia - Revista Eletrônica de Relações Internacionais do Centro Universitário Unieuro

ISSN: $1809-1261$

UNIEURO, Brasília, número 20, Janeiro-Junho de 2017, pp. 27-49.

América Latina: su naturaleza entrampada en la invención de su desarrollo

Al arribar a las costas de Las Indias, hoy denominadas Las Américas, los conquistadores europeos colisionan con una naturaleza, como expone Eduardo Gudynas (2011), alternadamente bella (rica) y salvaje.

La prodigalidad de recursos del Nuevo Mundo pone a andar los imaginarios europeos en un contexto en que la tradición medieval daba paso a la era de Renacimiento, donde a la razón se le otorgaría un papel protagónico, aunque en la Colonia persistieran rasgos medievales.

En ese contexto, la tensión y el conflicto de alteridad, o sea la negación de Europa hacia lo que luego se denominaría América, su otro, es un aspecto interesante de estudio para comprender el contexto socio-cultural, económico y político de América Latina contemporánea. Sin embargo, el presente texto prioriza la comprensión del concepto de naturaleza que los conquistadores europeos traían consigo, por entenderse como una de las claves para comprender la explotación ambiental y social que se lleva a cabo desde la llegada de los europeos al continente hasta la actualidad.

Gudynas (2011) afirma que la cosmovisión de los conquistadores rompe con la antigua tradición medieval de pensar al ser humano holísticamente en relación a la naturaleza- entendiendo ésta como un ser vivo- para adoptar e imponer una visión utilitarista y dualista entre ser humano y naturaleza. Esta perspectiva antropocéntrica que vislumbraba la naturaleza como una maquinaria de elementos vivos y no vivos, que podía y debía ser manipulada y manejada por el hombre [occidental], nace con el Renacimiento ${ }^{3}$, y será semilla para lo que luego -con algunas modificaciones de forma más que de fondo- fundará parte de la cosmovisión moderna occidental (GUDYNAS, 2011, p. 269270).

(...) la Edad Media pensaba en Dios como un creador cuya posición está fuera de la Naturaleza y anterior a ella. Esa concepción continua valiendo en

\footnotetext{
3 Gudynas (2011) señala que también existen investigadores que datan la visión antropocéntrica occidental desde sus raíces más antiguas. Es el caso de Leonardo Montenegro (2011) quién considera que las bases de nuestra cosmovisión occidental antropocentrísta viene de la tradición judeo-cristiana: "la cultura judeo-cristiana se basó en una mirada sobre el mundo, un mundo construido por su Dios, en que éste le otorga al «hombre» el poder sobre el universo: plantas, rocas, animales y mujeres, para su pleno disfrute y satisfacción (MONTENEGRO, 2011, p.325).
} 


\section{Artigo original}

Hegemonia - Revista Eletrônica de Relações Internacionais do Centro Universitário Unieuro ISSN: $1809-1261$

UNIEURO, Brasília, número 20, Janeiro-Junho de 2017, pp. 27-49.

la Edad Moderna. Sin embargo, el propio Hombre, cuyo lugar, durante la Edad Media, estaba situado dentro de la Naturaleza - como ella, el Hombre habría sido creado por Dios-, comenzó a asumir una posición externa a la Naturaleza, una posición casi divina. Abandona su menoridad y se eleva como dueño de la Naturaleza, como su dominador. La Naturaleza que, antes, era el ámbito de la creación, se torna objeto de ésta: objeto de su Ciencia y de su manipulación. La división cartesiana del mundo en dos partes - la res extensa (mundo de los cuerpos materiales) y la res cogitans (mundo del pensamiento) - es sintomática de la escisión entre el Hombre y la Naturaleza (KESSELRING, 2000, p.161-162, traducción propia).

Con este nuevo pensamiento mecanicista antropocéntrico llegan los europeos al continente, donde comienzan a controlar y manipular la naturaleza y a los pueblos indígenas que en ella vivían. Al considerarse una cultura superior, casi divina, los europeos emprenden la "domesticación" de la naturaleza "salvaje" para volverla "habitable". Esa empresa consideraba además, que los indígenas americanos también debían ser dominados ya que éstos "no eran capaces de dominar a la Naturaleza y «ennoblecerla» por medio de la cultura” (GUDYNAS, 2011, p. 272).

Los colonizadores se vuelcan decididamente a controlar esos ambientes salvajes, promoviéndose la minería, el cultivo de la tierra, la desecación de humedales, la construcción de canales, la caza intensiva, la tala de bosques, la introducción de especies productivas o la domesticación de aquellas salvajes que fueran de utilidad [...] La misión se entendió tanto como «conquistar» la Naturaleza, y «civilizar» los pueblos indígenas. En muchos casos, los indígenas eran considerados un elemento más de los ambientes que les rodeaban. Por esta razón la conquista y la imposición cultural iban de la mano (GUDYNAS, 2011, p. 271-272).

La visión instrumental de naturaleza sufre algunos cambios desde el siglo XVI hasta hoy. Durante la Colonia predomina una perspectiva que valoraba aisladamente los recursos de acuerdo a la utilidad presentada para el ser humano. Con ello se pierde la mirada de la naturaleza como conjunto. A mediados del siglo XIX, con la nuevas teorías de la botánica, la genética y la Teoría de la 


\section{Artigo original}

Hegemonia - Revista Eletrônica de Relações Internacionais do Centro Universitário Unieuro ISSN: $1809-1261$

UNIEURO, Brasília, número 20, Janeiro-Junho de 2017, pp. 27-49.

Evolución de Darwin, el concepto de ecosistema remplaza al de naturaleza. Con el paso del tiempo los ecólogos pasan a comprender los ecosistemas como "cuasi-organismos", atribuyéndoles un desarrollo temporal desde las condiciones más simples a las más complejas. Este pensamiento predomina durante el siglo XX y se difunde hacia América Latina. A partir de 1980, se introduce el concepto de biodiversidad, el que pasa a ocupar un lugar prominente en la discusión sobre el medio ambiente (GUDYNAS, 2011, p. 273-279).

A pesar de algunos cambios en forma, el fondo de nuestra concepción occidental moderna ${ }^{4}$ de la naturaleza no ha cambiado mayormente. En palabras de Arturo Escobar (1999):

En el ocaso del siglo XX, la cuestión de la naturaleza aún permanece sin resolver en cualquier orden social o epistemológico moderno. Con esto no solamente me refiero a "nuestra" incapacidad- la de los modernos- para encontrar formas de relacionarnos con la naturaleza sin destruirla, sino al hecho de que la respuesta dada a la "cuestión de la naturaleza" por las formas del conocimiento moderno -desde las ciencias naturales hasta las humanas- se ha quedado corta en tal búsqueda, a pesar del extraordinario salto que éstas parecen haber dado en décadas recientes. (...) El hecho de que la naturaleza haya llegado a ser pensada de manera separada de la gente y producida a través del trabajo, por ejemplo, está relacionado con la visión del "hombre" producida por el capitalismo y la modernidad (ESCOBAR, 1995, p. 273-274).

En este contexto de racionalidad antropocéntrica, sumado a la intensificación de un modelo capitalista de corte neoliberal, adoptado por gran parte de los países latinoamericanos durante este periodo, se propagan los conflictos socio-ambientales por toda la región como consecuencia de las prácticas de extracción de recursos naturales y de despojo de comunidades en nombre de la razón y en búsqueda de un nuevo anhelo -que reemplaza el ideal de un nuevo mundo-: el del "desarrollo". Esta búsqueda se traduce en la eterna contradicción que enfrenta nuestro Sur desde la Conquista: La maldición de su abundancia ${ }^{5}$.

${ }^{4}$ Néstor García Canclini (2003) plantea que en América Latina "las tradiciones aún no se fueron y la modernidad no terminó de llegar" (ibid. p. 17), por lo que propone preguntarnos si la modernidad deba o no ser un objetivo principal "como proclaman políticos, economistas y la publicidad de nuevas tecnologías" (ibid).

5 Término empleado por Alberto Acosta en su obra La Maldición de la Abundancia (2009). 


\section{Artigo original}

Hegemonia - Revista Eletrônica de Relações Internacionais do Centro Universitário Unieuro ISSN: $1809-1261$

UNIEURO, Brasília, número 20, Janeiro-Junho de 2017, pp. 27-49.

La invención del desarrollo y su racionalidad

El desarrollo, como concepto, ha sido definido y aplicado de formas diversas desde la segunda mitad del siglo veinte. Actualmente, tras la entrada de América Latina al mercado global y la adopción de una economía capitalista, el desarrollo se asocia al crecimiento económico.

En este sentido, el argumento central del concepto de desarrollo que se mantiene hasta hoy, según Alfonso Gumucio-Dagrón (2011), es:

que los países pobre necesiten tecnificarse, adquirir nueva tecnología para mejorar su producción e incrementar su producto nacional bruto; y para ello tienen que renunciar a sus tradiciones cuando éstas representen un freno para el concepto de desarrollo que quiere imponer Occidente. El desarrollo es concebido - ahora y entonces- como la necesidad de moldear las naciones pobres a imagen y semejanza de los países industrializados (GUMUCIODAGRÓN, 2011, p. 30).

El modelo de desarrollo mencionado ha generado impactos significativos en América Latina, especialmente a partir de la intensificación de las prácticas extractivas que han sido adoptadas como el camino primordial de los países del denominado Tercer Mundo, en busca de alcanzar algún día el estatus primermundista, poniendo en peligro la sobrevivencia de los ecosistemas y las comunidades que en ellas habitan [habitamos].

La búsqueda perpetua del desarrollo, a través de un modelo económico extractivista, constituye una trampa para las sociedades "no desarrolladas" o en vías de serlo:

"los países ricos en recursos naturales, cuya economía se sustenta prioritariamente en su extracción y exportación, encuentran mayores dificultades para desarrollarse (...). Estos países estarían atrapados en una lógica perversa conocida en la literatura especializada como "la paradoja de la abundancia", "la maldición de la abundancia de recursos naturales" (...) La gran disponibilidad de recursos naturales que caracteriza a estos países (...) tiende a distorsionar la estructura económica y la asignación de los factores productivos del país; redistribuye regresivamente el ingreso nacional 


\section{Artigo original}

Hegemonia - Revista Eletrônica de Relações Internacionais do Centro Universitário Unieuro ISSN: $1809-1261$

UNIEURO, Brasília, número 20, Janeiro-Junho de 2017, pp. 27-49.

y concentra la riqueza en pocas manos. Esta situación se agudiza por una serie de procesos endógenos de carácter ‘patológico' que acompañan a la abundancia de esos recursos naturales.” (ACOSTA, 2009, p. 22-23).

Es así como, a partir de lo visto anteriormente, el desarrollo se convierte en una trampa viciosa al ser, por un parte, considerado el único camino- impuesto por las grandes potencias mundiales en un contexto globalizado - posible para salir de un estado de "subdesarrollo", y a la vez ser el mismo camino que lleva a los países a empeorar las situaciones de pobreza, marginalidad y vulnerabilidad socio-ambiental y económica que viven.

La torpeza de los seres humanos, radica en su soberbia que nos impide ver que esto que llamamos «desarrollo» no sólo ha creado imaginarios de bienestar (para unos pocos) sino que ha implicado miseria para la mayoría de la humanidad y destrucción para el mundo (ver Escobar, 1998) (MONTENEGRO, 2011, p.326).

En busca de comprender cómo aparece el desarrollo de modo eldoradista ${ }^{6}$, como la eterna esperanza de los países para salir de su "estado de subdesarrollo", es relevante considerar que las políticas de desarrollo fueron implementadas y difundidas fuertemente en América Latina tras la Segunda Guerra Mundial y la posterior polarización de los bloques ideológicos de la Guerra Fría que buscaban nuevas zonas de influencia.

Gumucio-Dagrón (2011) afirma que fue necesario, debido a la evolución de la política internacional, encontrar nuevas estrategias de influencia que no incluyeran la fuerza, sobresaliendo estrategias como la cooperación militar y auxilio para el desarrollo, con el objetivo de conservar la relación entre las potencias y sus ex colonias.

La cooperación internacional se desarrolla en los "patios traseros" de las potencias occidentales con el fin de colocar su producción industrial y mantener su influencia política y económica. El mundo está claramente dividido como un tablero de ajedrez en zonas de influencias. Esa estrategia de largo plazo, sin embargo, requiere un componente de información y

\footnotetext{
${ }^{6}$ Concepto utilizado por Maristella Svampa (2013, p.35) refiriéndose al imaginario de una América Latina como un lugar de abundancias de recursos naturales.
} 


\section{Artigo original}

Hegemonia - Revista Eletrônica de Relações Internacionais do Centro Universitário Unieuro ISSN: $1809-1261$

UNIEURO, Brasília, número 20, Janeiro-Junho de 2017, pp. 27-49.

propaganda que era indispensable en el contexto de la Guerra Fría y lo es cada día más (GUMUCIO-DAGRÓN, 2011, p.29).

Una de las premisas de la difusión del concepto de desarrollo en América Latina, impulsada fuertemente por Estados Unidos, señala que las culturas autóctonas son un obstáculo para la modernización de los pueblos, por lo que hay dejar estos atrás. En palabras de Gumucio-Dagrón (2011), se observa que durante décadas se impuso la creencia, que tenía como base la superioridad tecnológica y económica, de que los países más pobres, denominados tercermundistas, eran responsables de su propia pobreza por tanto el camino a seguir, para salir de esta situación, sería el de aquellos "desarrollados" que ya habían pasado por la situación Latinoamérica en etapas anteriores.

Los modelos basados en la teoría de la modernización -dominante en muchos organismos de cooperación y desarrollo- todavía estiman que son razones culturales las que impiden que los pueblos del Tercer Mundo den el salto hacia una vida "moderna". Implícitamente, estas teorías defienden que el objetivo de todos los pueblos debería ser la aspiración a una vida material y espiritual como la que se conoce en el mundo occidental y que para lograrlo es imprescindible sacrificar las conquistas sociales, y deshacerse de creencias, tradiciones y prácticas culturales que son un freno para la modernización (LERNER, 1958 apud GUMUCIO-DAGRÓN, 2011, p. 30).

Geopolítica de una crisis ambiental

Tras la utilización de la difusión y propaganda proveniente de Estados Unidos - especialmente desde los centros universitarios del país- en América Latina se implementaron acuerdos globales fomentados por los países industrializados (GUMUCIO-DAGRÓN, 2011, p.30) como una segunda herramienta estratégica de control y dominación sobre la región. Un punto de inflexión en la situación actual de América Latina es uno de estos acuerdos: el Consenso de Washington.

Luego del decaimiento del modelo de Industrialización por Sustitución de Importaciones (ISI)- modelo económico adoptado de modo general por América Latina desde 1933- y junto con la transición política- entre 1982 a 1990- de un periodo de dictadura a democracia, los países 


\section{Artigo original}

Hegemonia - Revista Eletrônica de Relações Internacionais do Centro Universitário Unieuro ISSN: $1809-1261$

UNIEURO, Brasília, número 20, Janeiro-Junho de 2017, pp. 27-49.

latinoamericanos implementan una reforma en la estructura económica adoptando, a finales de la década de los ochenta, una economía de mercado como modelo a seguir (BÉJAR, 2004, p.19). Así, Ramón Casilda Béjar, economista y consultor del Banco Interamericano de Desarrollo, expone:

Latinoamérica, ante las nuevas realidades, tras la caída del muro de Berlín y próxima a iniciarse la década de los noventa, observó la necesidad de fortalecer las recién instauradas economias de mercado, herederas de una situación de desestabilización, de excesiva protección y regulación. Esta búsqueda de un modelo lo más estable, abierto, liberalizado, particularmente orientado a los países de América Latina, nace en 1989 en el llamado «Consenso de Washington», donde se trató de formular un listado de medidas de política económica para orientar a los gobiernos de países en desarrollo y a los organismos internacionales (Fondo Monetario Internacional, Banco Mundial y Banco Interamericano de Desarrollo [FMI, BM y BID]) a la hora de valorar los avances en materia económica de los primeros al pedir ayuda a los segundos (BÉJAR, 2004, p. 19).

Para la primera formulación del Consenso, bajo el cargo de John Williamson ${ }^{7}$, se utilizaron diez enunciaciones como base, entre las cuales, se pueden mencionar: cambios en las prioridades del gasto público (reducir los gastos públicos en vez de aumentar la recaudación tributaria); reforma fiscal: tipos de interés (determinados por el mercado); tipo de cambio (determinadas por las fuerzas del mercado); liberalización comercial y liberalización de las importaciones; política de apertura respecto a la inversión extranjera directa (IED); política de privatizaciones; política desreguladora; fortalecimiento de derechos de propiedad (BÉJAR, 2004, p. 20-23).

El Consenso de Washington, según lo ilustrado más arriba, es una primera apertura plena de los países latinoamericanos al mercado mundial. Tal como se ha mencionado anteriormente, la búsqueda del desarrollo a partir de la importación de tecnologías, la apertura y la flexibilización de mercados y difusión de ideales conceptuales ha sido contraproducente en cuanto al bienestar de nuestras poblaciones. Así, Ramón Casilda Béjar concluye:

En definitiva, consideramos el Consenso de Washington como el resultado de una profunda evolución de las ideas, que reflejó la vigencia progresivamente generalizada de una filosofía basada en los principios fundamentales de

\footnotetext{
${ }^{7}$ Economista del Instituto de Economía Internacional y miembro del Banco Mundial cuando redactó las formulaciones del Consenso.
} 


\section{Artigo original}

Hegemonia - Revista Eletrônica de Relações Internacionais do Centro Universitário Unieuro

ISSN: $1809-1261$

UNIEURO, Brasilia, número 20, Janeiro-Junho de 2017, pp. 27-49.

democracia y libertad: «dando predominio a los derechos individuales frente a los colectivos». Adviértase que las políticas de reforma propuestas fueron aplicadas en toda América Latina en ocasiones minuciosamente, en otras parcialmente, y voluntariamente en otros países en desarrollo; sin embargo se constata, iniciado el siglo XXI: «que los resultados generalmente obtenidos han sido más bien desalentadores» (BÉJAR, 2004, p. 23-24).

Los resultados "desalentadores" a los que hace referencia Béjar (2004) representan el aumento y generalización de la pobreza; el estancamiento económico "real" y los indicadores de desarrollo social que fueron en sus palabras, “apenas más favorables”. Así al terminar la década de puesta en practica del Consenso, Latinoamérica acabó siendo la región con mayor desigualdad respecto a la distribución del ingreso y tierras (ibid., p. 25).

A pesar del fracaso del Consenso de Washington durante la década de los noventa, la socióloga argentina Maristella Svampa (2013) afirma que actualmente nos encontramos ante un nuevo Consenso que continua ${ }^{8}$ y ahonda en las bases neoliberales dejados por su antecesor. "En el último decenio, América Latina realizó el pasaje del Consenso de Washington, asentado sobre la valorización financiera al «Consenso de los Commodities», basado en la exportación de bienes primarios en gran escala" (SVAMPA, 2013, p. 30).

$\mathrm{El}$ «Consenso de los Commodities» subraya el ingreso de América Latina en un nuevo orden económico y político-ideológico, sostenido por el boom de los precios internacionales de las materias primas y los bienes de consumo demandados cada vez más por los países centrales y las potencias emergentes. Este orden va consolidando un estilo de desarrollo neoextractivista que genera ventajas comparativas, visibles en el crecimiento económico, al tiempo que produce nuevas asimetrías y conflictos sociales, económicos, ambientales y político-culturales. Tal conflictividad marca la apertura de un nuevo ciclo de luchas centrado en la defensa del territorio y

\footnotetext{
8 A pesar de que Svampa (2013) afirma que existe cierta continuidad, deja claro que la actual etapa también se puede leer en términos de rupturas con el Consenso de Washington, al existir diferentes centros, el Consenso de Washington por su parte focalizó la valorización financiera y llevó a cabo una política de privatizaciones, llevando al Estado a un rol de "agente metarregulador". También, durante el Consenso de la década de los ochenta se realizó una especie de homogeneización política en América Latina pauteada por esquemas neoliberales. En este sentido, el "Consenso de los Commodities" difiere de su antecesor al pautear como tema central la “implementación masiva de proyectos extractivos orientados a la exportación”, otorgando al Estado, en este caso, un rol más flexible (SVAMPA, 2013, p.36).
} 


\section{Artigo original}

Hegemonia - Revista Eletrônica de Relações Internacionais do Centro Universitário Unieuro ISSN: $1809-1261$

UNIEURO, Brasília, número 20, Janeiro-Junho de 2017, pp. 27-49.

del ambiente así como en la discusión sobre los modelos de desarrollo y las fronteras mismas de la democracia (SVAMPA, 2013, p.30).

De esta manera, la situación geopolítica del siglo XX y XXI, cimentada en el pensamiento racional, heredado de la modernidad y que llegó a América junto con los conquistadores en el siglo $\mathrm{XV}$, hoy ha traído como consecuencia un modelo que ha provocado devastadoras consecuencias sociales y medioambientales que, a partir de la perspectiva de este trabajo se considera urgente revisar desde la complejidad histórica y multifactorial de la "crisis ambiental" que caracteriza a este siglo que comienza. De la misma forma se considera urgente reconocer el ciclo de lucha y defensa a una naturaleza que hoy se entiende desde nuestro sur a partir de una perspectiva territorial que incluye una postura y una lucha política de los seres, humanos y no humanos, que en ella habitamos.

Crisis de la naturaleza [y] [de] la razón

Retomando la revisión histórica expuesta al comienzo de este trabajo, la concepción de naturaleza del pensamiento moderno difundida también en América Latina concluye en la década de los ochenta, desmoronándose la visión de ecosistema como un "cuasi organismo" para pasar a una comprensión de naturaleza y/o ecosistema como una dinámica desordenada e imprevisible.

Unos veinte años antes, durante la década de los sesenta y de manera paralela a la implementación de las diversas estrategias geopolíticas de las potencias mundiales en América Latina a través de la difusión, propaganda, programas pro desarrollo y la apertura al mercado mundial mencionado anteriormente-, comienzan a surgir las primeras voces de resistencia que visibilizan una crisis socio-económica y, especialmente, medioambiental a nivel planetario sin precedentes.

Por lo menos desde la década de 1960, proliferaron las alertas sobre una creciente problemática ambiental, debido a la contaminación, pérdida de áreas llamadas naturales, y extinción de especies emblemáticas. La vieja imagen de una Naturaleza agresiva y todopoderosa, poco a poco, dio paso al ser una Naturaleza frágil y delicada ... En la década de 1970 estalla la polémica sobre los límites ecológicos a la idea de crecimiento económico perpetuo, donde queda en evidencia que los sistemas económicos y 


\section{Artigo original}

Hegemonia - Revista Eletrônica de Relações Internacionais do Centro Universitário Unieuro ISSN: $1809-1261$

UNIEURO, Brasília, número 20, Janeiro-Junho de 2017, pp. 27-49.

productivos están, en realidad, dentro de un sistema mayor, ecológico, que tiene ciertos límites y capacidades (GUDYNAS, 2011, p.277).

Para Enrique Leff, a través de estos movimientos que brotan a partir de la década de los sesenta, comienza a surgir:

Una percepción de la destrucción de la naturaleza, de que algo anda mal en la concepción de progreso, en el dominio de la ciencia sobre la naturaleza, en las promesas incumplidas del desarrollo. Se va configurando una conciencia ambiental sobre los límites de crecimiento, la irracionalidad de la racionalidad económica dominante, la destrucción de las bases ecológicas de la sustentabilidad del planeta, el circulo perverso de la degradación ambiental y pobreza (LEFF, 1994, s/p).

Leff (1994) expone que el avance de estas ideas que cuestionan la racionalidad económica, base de la modernidad y productor de la crisis civilizatoria, permite el surgimiento del ecodesarrollo, movimiento que plantea la necesidad de transformar y crear nuevos estilos de vida y modos de producción "en condiciones y potencialidades ecológicas de cada región, así como la diversidad étnica y la capacidad propia de las poblaciones para autogestionar sus recursos naturales y sus procesos productivos" proponiendo así un modelo de desarrollo alternativo al imperante (LEFF, 1994, s/p).

Sin embargo, al llegar la década de los ochenta este movimiento se difumina hasta desaparecer producto de la configuración y fortalecimiento de programas y consensos neoliberales como consecuencia de la crisis económica vivida por América Latina, generando que los gobiernos latinoamericanos prioricen el crecimiento económico ante todo.

En este proceso se configuraron los programas neoliberales de diferentes países, al tiempo que avanzaban y se complejizaban los problemas ambientales del orbe. En ese momento empieza a caer en desuso el discurso del ecodesarrollo y al ser suplantado por la retórica del desarrollo sostenible. Si bien muchos de los principios de ambos discursos son afines, las estrategias de poder del orden económico dominante van modificando el 


\section{Artigo original}

Hegemonia - Revista Eletrônica de Relações Internacionais do Centro Universitário Unieuro

ISSN: $1809-1261$

UNIEURO, Brasília, número 20, Janeiro-Junho de 2017, pp. 27-49.

discurso ambiental crítico para someterlo a la racionalidad del crecimiento económico (LEFF, 1994, s/p).

Así, según Leff (1994), el discurso ambientalista de la década de los setenta, que llamaba a frenar el crecimiento económico y la necesidad de instauración de un modelo de desarrollo alternativo se pasa a uno de corte neoliberal que borra las fronteras y produce contradicciones entre crecimiento económico y ambiente?

Gudynas (2011) también se refiere al giro que ocurrió durante la década de los ochenta respecto a las concepciones de la naturaleza, estableciendo que comienza a existir una "economización" de ésta, "en el sentido de ampliar el concepto de capital hasta englobarla y poder ingresarla al mercado", ya en los ochenta se puede comenzar a observar el concepto de Capital Natural (GUDYNAS, 2011, p. 278).

El hecho notable ha sido la intensidad con que estas posturas se han difundido en América Latina. En pocos años cobró notoriedad bajo el llamado ambientalismo de «mercado libre» (por ejemplo, Anderson y Leal, 2011), con una influencia que se extendió a otros campos al calor de las reformas neoliberales que estaban en marcha en América Latina (...) Estas posturas expanden la racionalidad económica, de base neoclásica manteniendo el mismo propósito de instrumentalización y manipulación (GUDYNAS, 2011, p.278).

Por otra parte, Leff (1994, s/p) afirma que "la geopolítica de la sustentabilidad opera como una estrategia fatal, como una precipitación hacia la catástrofe". Para el autor mexicano, esta geopolítica, fruto de una racionalidad moderna (economicista) es la responsable ante la actual crisis ambiental al fundarse "en el proyecto científico de la modernidad, [que] ha llegado a escudriñar los núcleos más íntimos de la naturaleza (LEFF, 2004, ix-xi).

A pesar del escenario poco alentador bosquejado hasta aquí, Enrique Leff plantea una salida a la trampa de la razón moderna, que sería la deconstrucción de ésta y la creación de una nueva

\footnotetext{
${ }^{9}$ El concepto de ambiente cobra gran importancia como una base de la propuesta política del ecodesarrollo. En este contexto la noción de ambiente aborda más que la ecología: "El ambiente aparece como un nuevo potencial de desarrollo, basado en la articulación sinergética de la productividad ecológica del sistema de recursos naturales, de la productividad de sistemas tecnológicos apropiados, y de la productividad cultural que proviene de la movilización de los valores conservacionistas, de la creatividad social y de la diversidad cultural" (LEFF, 1994, s/p).
} 


\section{Artigo original}

Hegemonia - Revista Eletrônica de Relações Internacionais do Centro Universitário Unieuro ISSN: $1809-1261$

UNIEURO, Brasília, número 20, Janeiro-Junho de 2017, pp. 27-49.

racionalidad: una racionalidad ambiental. Este autor postula que ésta no puede sólo existir desde la teoría, sino que deberá necesariamente poseer un carácter práctico, político, de mediación entre lo material y lo simbólico (perdido por la racionalidad moderna) y sobre todo emancipador del pensamiento creativo.

... la construcción de una racionalidad ambiental, no es tan sólo una empresa filosófica y teórica. Ésta arraiga en prácticas sociales y en nuevos actores políticos. Es al mismo tiempo un proceso de emancipación que implica la descolonización del saber sometido al dominio del conocimiento globalizador y único, para fertilizar los saberes locales. La construcción de la sustentabilidad es el diseño de nuevos mundos de la vida, cambiando el sentido de los signos que han fijado los significados de las cosas (...) La racionalidad ambiental se forja en una ética de la otredad, en un diálogo de saberes y una política de la diferencia, más allá de toda ontología y de toda epistemología que pretenden conocer y englobar al mundo, controlar la naturaleza y sujetar a los mundos de la vida (LEFF, 2004, xiii, xv).

Nuevas Racionalidades e Infancia

La crisis civilizatoria vivida desde la década de los sesenta en adelante fue lo que motivó y generó resistencias que finalmente se convirtieron en un movimiento, que a pesar de haberse difuminado, dejó como herencia su pensamiento crítico y propuestas que hoy seguimos discutiendo en diversos rincones del planeta. En este sentido, y como muchas veces ocurre, las crisis pueden convertirse en gatilladoras de cambio social.

Como ha sido expuesto en el presente trabajo, la crisis ambiental que hoy enfrenta el mundo y, específicamente, América Latina, demanda nuevas racionalidades. La historia ha demostrado que no es posible encontrar salidas a las crisis usando como marco de referencia el mismo modelo que las provocaron, como parece intentarlo actualmente el "desarrollo sustentable", apropiado por el mercado financiero-. 


\section{Artigo original}

Hegemonia - Revista Eletrônica de Relações Internacionais do Centro Universitário Unieuro ISSN: $1809-1261$

UNIEURO, Brasília, número 20, Janeiro-Junho de 2017, pp. 27-49.

La crisis ambiental que hoy vivimos no se expresa de forma homogénea y simultánea a nivel mundial, o siquiera a nivel regional, más bien se expresa a través de diversas manifestaciones que hoy se traducen, especialmente desde una perspectiva territorial, en la proliferación de conflictos socioambientales en la región, entendiendo éstos como:

ligados al acceso y control de los bienes naturales y el territorio, que suponen, por parte de los actores enfrentados, intereses y valores divergentes en torno de ellos, en un contexto de gran asimetría de poder. Estos conflictos expresan diferentes concepciones sobre el territorio, la naturaleza y el ambiente, al tiempo que van estableciendo una disputa acerca de lo que se entiende por desarrollo y, de manera más general, por democracia (SVAMPA, 2013, p.39-40).

Las asimetrías propias de los conflictos ambientales se pueden traducir, en mayor escala, a lo que Vandana Shiva (2001) define como apartheid ambiental:

En un mundo de comercio global y liberalizado, del poder y el control, los recursos se trasladan de los pobres a los ricos y la contaminación se traslada de los ricos a los pobre. El resultado es un apartheid ambiental a escala mundial (SHIVA, 2011, p.1).

En estos territorios se encuentran las "áreas de sacrificio"10, que son las más afectadas por los proyectos extractivistas $y$, que antes de su aparición, ya se encontraban en una situación de desigualdad social, emplazadas en zonas ricas, en cuanto a la naturaleza, y pobres en cuanto a recursos económicos, oportunidades laborales y niveles de bienestar general para la población. En este contexto y entre quienes viven en este territorio condenado a lo que se denomina la "maldición de la abundancia", son las mujeres, las niñas y los niños aquellos y aquellas que permanecen al final de la larga lista de marginalización (CEPAL, 2013), convirtiéndose en meros daños colaterales para el mercado mundial, invisibilizados históricamente como actores relevantes en la esfera pública mientras viven en la esfera privada de sus hogares las consecuencias más crudas de las desigualdades socio-económicas de vivir en zonas de contaminación ambiental en América Latina.

\footnotetext{
${ }^{10}$ Maristela Svampa (2013) se refiere a «áreas de sacrificio» como zonas que, en función de una mirada productivista y eficientista del desarrollo que descalifica otras lógicas de valorización de los territorios, son consideradas como socialmente vaciables y sacrificables en pro del progreso selectivo (SVAMPA, 2013, p.34).
} 


\section{Artigo original}

Hegemonia - Revista Eletrônica de Relações Internacionais do Centro Universitário Unieuro ISSN: $1809-1261$

UNIEURO, Brasília, número 20, Janeiro-Junho de 2017, pp. 27-49.

A pesar del rápido avance de los proyectos extractivistas que arrastran con ellos problemáticas múltiples e interrelacionadas, se comienza a visualizar el brote de diversas resistencias eco-territoriales ${ }^{11}$ que se articulan rápidamente trenzando una red de defensa y lucha por la tierra llevada a cabo por grupos y comunidades que dejan a un lado el azar y la condena de la abundancia para empoderarse y articularse, enfrentando los engranajes de la geopolítica internacional en busca de la sobrevivencia y sustentabilidad de la vida humana y de los diferentes seres que componen los ecosistemas afectados.

Lo anterior es concordante con lo expuesto por Leff en relación a que la racionalidad ambiental debe construirse "en los procesos sociales de reapropiación de la naturaleza. De esta manera se va articulando un pensamiento y un discurso con un conjunto de prácticas productivas y procesos políticos" (LEFF, 2004, xviii).

Estos lenguajes de valoración acerca de la territorialidad han ido impulsando la sanción de leyes y normativas, incluso de marcos jurídicos que apuntan a la construcción de una nueva institucionalidad ambiental, en oposición a las actuales políticas públicas de corte extractivista (...). En términos generales, y por encima de marcas específicas (...), la dinámica de luchas socioambientales en América Latina da lugar a lo que hemos denominado «giro ecoterritorial», esto es, un lenguaje común que ilustra el cruce innovador entre matriz indígena comunitaria, defensa del territorio y discurso ambientalista: bienes comunes, soberanía alimentaria, justicia ambiental y «buen vivir» (SVAMPA, 2013, p. 40).

De esta manera, en el actual y crítico escenario socio-ambiental latinoamericano, la referencia al «giro ecoterritorial» y su carácter diverso, participativo y local, expuesto por Maristella Svampa, sumada a la propuesta de creación de una racionalidad ambiental, planteada por Enrique Leff, junto con la necesidad urgente de comenzar a visualizar posibilidades de transformaciones socioambientales, políticas y económicas, aparece(n) la(s) infancia(s).

\footnotetext{
11 Maristella Svampa (2013) observa una articulación de saberes que se comienza a generar entre diversos actores, a saber "movimientos indígenas-campesinos, movimientos socioambientales, ONG ambientalistas, redes de intelectuales y expertos, colectivos culturales", en torno a los conflictos socio-ambientales, creándose lo que ella refiere como un "diálogo de saberes y disciplinas que conduce a la emergencia de un saber experto independiente de los discursos dominantes y a la valorización de los saberes locales"(SVAMPA, idim., p. 40-41).
} 
Artigo original

Hegemonia - Revista Eletrônica de Relações Internacionais do Centro Universitário Unieuro

ISSN: 1809-1261

UNIEURO, Brasília, número 20, Janeiro-Junho de 2017, pp. 27-49.

Para comprender las diversas visiones, temporalidades y geografías de las comunidades y naciones insertas en una economía global, se plantea la necesidad de incorporar las percepciones de niñas y niños que viven en territorios enfrentados a conflictos socioambientales, considerando así las formas de ver y vivir la naturaleza que tienen sujetos que habitualmente son excluidos como agentes con potencial de transformación social, a pesar de vivir cotidianamente las consecuencias de las problemáticas estructurales de las que son parte. En ese sentido, las visiones infantiles permiten remirar el mundo desde un posicionamiento que desafía la racionalidad moderna y adultocéntrica, favoreciendo el análisis de los conflictos socioambientales a partir de una mirada más compleja, entrelazada e interdisciplinar.

Es así como la propuesta de este texto se incorpora en la discusión teórica del campo de los estudios de infancia, pensando en las posibilidades de considerar a las y los niños como agentes sociales en contextos de contaminación y conflicto socioambiental.

Desde finales de la década de los ochenta, y con mayor fuerza durante la década de los noventa, como fruto de la Convención de los Derechos del Niños en 1989, surge desde las ciencias sociales un acentuado interés en realizar investigaciones relativas a la niñez, construyéndose una vasta agenda interdisciplinaria que buscaba acercarse a las y los niños, emergiendo así un nuevo campo de estudio, los Childhood Studies (SOSENSKI, 2011, p. 44).

Este nuevo paradigma de investigación de infancia tiene como eje central la concepción de “niños y niñas como actores sociales que tienen mucho que decir sobre el mundo, siendo personas que pueden ser incentivadas a sacar la voz a través de la adopción de investigaciones con métodos etnográficos y participativos" (JAMES; PROUT, 1990 apud JAMES, 2007, p. 262). Un campo en que las y los investigadores tratan de comprender "cómo las niñas y los niños construyen su niñez, cómo construyen cultura, cuáles son y han sido sus perspectivas sobre la sociedad y sus problemas o cómo la niñez se convierte en un elemento que estructura la vida social o económica" (SOSENSKI, 2001, p.44).

Este nuevo paradigma no viene sin dificultades, como afirman los investigadores Fine y Sandstrom (1988), el llegar a comprender el mundo desde la infancia es complejo. La dificultad recae sobre el hecho de que las niñas y los niños pertenecen a un grupo, que como pocos en nuestra cultura, nos son tan cercanos y lejanos simultáneamente. El fuerte vínculo que los adultos compartimos con los infantes responde a que en algún momento del pasado fuimos ellas y ellos. 


\section{Artigo original}

Hegemonia - Revista Eletrônica de Relações Internacionais do Centro Universitário Unieuro ISSN: $1809-1261$

UNIEURO, Brasília, número 20, Janeiro-Junho de 2017, pp. 27-49.

Con el objetivo de enfrentar este desafío, a raíz de sus investigaciones, Santamaría y Bothert (2011) proponen dar espacio a las niñas y niños como sujetos capaces de "interiorizar las experiencias que le ofrece el medio, transformándolas en conocimiento y en palabras, un niño portador de múltiples saberes, que si el medio le da la oportunidad podrá ser protagonista de importantes cambios personales e interpersonales" (SANTAMARÍA; BOTHERT, 2011, p. 68). Ellas afirman:

(...) niño como sujeto de saber y de conocimiento. Este niño portador de una cultura, pero a su vez creador de la misma, que aprende a escuchar y a expresarse en distintos lenguajes, cualquiera sea su edad. Niño que participa activamente en la construcción de su propio conocimiento y en el de los otros, que interactúa con el otro, desde el momento en que es engendrado y que es capaz de generar importantes cambios mentales, paradigmáticos y sociales (...) sin embargo su voz aún no se escucha, sus expresiones la mayoría de las veces son acalladas, sus pensamientos no son tenidos en cuenta (SANTAMARÍA; BOTHERT, 2011, p. 68).

Desde una perspectiva espacial, Christopher Day (2007) afirma que adultos y niños ven el mundo de modos diferentes. Por una parte, la experiencia adulta se centra en cómo nosotros usamos los lugares: nosotros sabemos para qué sirven. Por otro lado, para los infantes se trata de qué dicen los lugares, cómo los conocen y cómo los experiencian. Para las niñas y niños el mundo es fresco- un gran exploratorium sensorial-. Ellos trabajan por el procesos; los adultos trabajan para lograr un resultado final. Por lo tanto, para los adultos, los lugares son propósitos predefinidos; y para los niños, son oportunidades para hacer cosas: "esta es la distinción crítica” (DAY, 2007, p. 3-4, traducción propia).

Tener una mayor comprensión sobre la dimensión espacial que diferencia nuestras perspectivas de las infantiles cobra gran relevancia en el marco de conflictos ambientales debido a que, a partir de los discursos y prácticas que las y los niños generan en relación al espacio que habitan se procura comprender la noción que tienen del espacio y de esta forma vislumbrar el conflicto desde su complejidad y pensar el remodelaje de la sociedad, incluyendo a las y los niños de las generaciones actuales.

Es en estos términos que esta reflexión teórica sitúa en el centro de la discusión a niñas y niños como agentes, quienes a través de sus prácticas y discursos, recrean el mundo social. Las 
Artigo original

Hegemonia - Revista Eletrônica de Relações Internacionais do Centro Universitário Unieuro

ISSN: 1809-1261

UNIEURO, Brasília, número 20, Janeiro-Junho de 2017, pp. 27-49.

prácticas recreativas de una infancia sumergida en conflictos ambientales son un presagio de las formas en las que desde la base se resinifica la realidad latinoamericana.

De esta forma se cree fundamental considerar, desde una mirada interdisciplinar y multidimensional inserto en el terreno de los estudios de infancia, a las y los niños como actores relevantes en las estructuras sociales capaces de realizar "procesos de significaciones, que estructurados y consolidados en sistemas simbólicos, constituyen culturas en su relación entre ellos y ellas, con los adultos y con la cultura y con la sociedad en general” (GOBBI; FINCO, 2013, p.63). Es por esto que el presente trabajo invita a encontrar en el tejido de las diversas relaciones y contextos socio-culturales las perspectivas infantiles para incluirlas en las discusiones eco-territoriales y sociales de la región.

\section{REFLEXIONES FINALES}

A partir de finales del siglo pasado el mundo comenzó a verse enfrentado y afectado por una crisis medioambiental de escala planetaria sin precedentes. En este contexto, América Latina, como también es el caso de las demás naciones pertenecientes al Tercer Mundo, comienza a sufrir asimétricamente - respecto a las potencias primermundistas- una serie de problemáticas socioculturales, económicas y políticas, consecuencia de la rápida proliferación de los conflictos socioambientales, donde las comunidades más afectadas comienzan a verse enfrentadas a la pérdida, erosión, desposesión y contaminación de sus territorios.

A partir del breve abordaje histórico de las nociones de naturaleza en América Latina desde el siglo XVI hasta la actualidad, sumado a una visión general de las principales estrategias geopolíticas llevadas a cabo durante la segunda mitad del siglo XX por los países industrializados - guiados por su racionalidad economicista propia de la modernidad y difundida en América Latina a través de las concepciones como desarrollo, que tras su imagen positiva entraman una serie de factores y acciones económicas, socio-culturales, ideológicos y políticos-, se ha llevado a los países Sur a una situación socio-económico y territorial nefasta.

Tras la contextualización histórica, geopolítica e ideológica, de la razón moderna, entra en escena la infancia como elemento relevante de considerar al analizar los conflictos socio-ambientales. Así, a partir de la perspectiva de las y los niños, se cree posible aportar a la creación de una nueva 


\section{Artigo original}

Hegemonia - Revista Eletrônica de Relações Internacionais do Centro Universitário Unieuro ISSN: $1809-1261$

UNIEURO, Brasília, número 20, Janeiro-Junho de 2017, pp. 27-49.

racionalidad, que busca alejarse del dogma de la racionalidad moderna. Es en esta ventana, que la presente investigación propone que en las miradas infantiles puedan existir soluciones locales a las problemáticas vividas por las comunidades insertas en territorios de conflicto socio-ambiental.

La perspectiva infantil puede ser fuente de una nueva racionalidad ambiental, racionalidad que sólo podrá ser exitosa si la teoría es acompañada de una práctica que hace converger a una diversidad de actores en torno a una problemática medioambiental o territorial que Maristella Svampa (2013) observa y posteriormente denomina "giro ecoterritorial". Una real ciudadanía debe ser abordada más allá de los límites de la cognición adulta. Es por esto que se propone un enfoque que incluya las perspectivas infantiles en territorios dominados por conflictos socioambientales en la búsqueda de nuevos entendimientos que de otra forma de podrían pasar por alto.

Finalmente, considerar a las niñas y niños como agentes sociales supone entender la diferencia en su comprensión de mundo y en las formas particulares que tienen de vivir bajo condiciones de tensión ambiental. De esta manera se abre una ventana hacia una mirada del mundo. Las visiones infantiles se convierten en elementos esenciales para movimientos de resistencia socioambientales y también, en la generación de una nueva racionalidad que visa el bienestar de todos los seres, humanos y no humanos, del planeta.

\section{BIBLIOGRAFÍA}

ACOSTA, Alberto, La Maldición de la Abundancia, Quito, Ediciones Abya-Yala, 2009, 239 p.

BEJÁR, Ramón, “América Latina y el Consenso de Washington”, In, Boletín Económico de Ice, num. 2803, España, 26 de abril-2 de mayo, 2004, 19-38 pp.

CANCLINI, Néstor. Culturas Híbridas: Estratégias para Entrar e Sair da Modernidade, tradução de Heloísa Pezza, Ana Regina, 4 ed., São Paulo, Editora Universidade de São Paulo, 2003. 205 p.

DAY, Christopher, Environment and Children. Passive Lessons from Everyday Environment, Oxford, Elsevier, 2007, 312 pp.

DOMÍNGUEZ, Gisela. "Mujer, Naturaleza y Medio Ambiente Beijing +20", In, XII Conferencia Regional sobre la Mujer de América Latina y el Caribe, CEPAL, Santo Domingo, 15 a 18 de octubre de 2014. 
Artigo original

Hegemonia - Revista Eletrônica de Relações Internacionais do Centro Universitário Unieuro ISSN: 1809-1261

UNIEURO, Brasília, número 20, Janeiro-Junho de 2017, pp. 27-49.

http://www.cepal.org/12conferenciamujer/noticias/paginas/0/49920/Gisela-Alonsopresentacion-MRBeijing-CRM_XII.pdf

ESCOBAR, Arturo. El Final Salvaje. Naturaleza, Cultura y Política en la Antropología Contemporánea. Bogotá, Cultura libre, diciembre, 1999, 418 p.

FINE, Gary, SANDSTROM, Kent, Knowing children: Participant observations with minors, Qualitative Research Methods, v. 15, Beverly Hills, SAGE, 1988, 85 p.

GOBBI, Márcia, FINCO, Daniela, "Meninas e meninos em assentamentos do MST: representações e diferentes modos de ver e sentir da infância do campo", In, Infâncias do Campo, Belo Horizonte, Autêntica Editora, 2013, 59-76 pp.

GUDYNAS, Eduardo, "El buen vivir más allá del extractivismo”, In, La Maldición de la Abundancia. Quito, Ediciones Abya-Yala, 2009, 15-20 pp.

GUDYNAS, Eduardo, "Imágenes, ideas y conceptos sobre la naturaleza en América Latina”, In, Cultura y Naturaleza: aproximaciones a propósito del bicentenario de la independencia de Colombia, Bogotá: Jardín Botánico, José Celestino Mutis, mayo 2011, 277-294 pp.

GUMUCIO-DAGRÓN, Alfonso, "Comunicación para el cambio social: clave del desarrollo participativo" In, Signo y Pensamiento, 58 eje temático, vol. XXX, Bogotá, enero-junio 2011, 26-39 pp.

JAMES, Allison, "Giving Voice to Children's Voices: Practices and Problems, Pitfalls and Potentials”, In, American Anthropologist. v. 109, n.2, Washington, jun. 2007, 261-272 pp.

KESSELRING, Thomas, "O Conceito de Natureza na História do Pensamento Ocidental” IN, Episteme. n.11, Porto Alegre, julho-dezembro. 2000.153-172 pp.

LEFF, Enrique, Racionalidad Ambiental. La Reapropiación Social de la Naturaleza, 1 ed., México, Siglo XXI, 2004, 509 p.

LEFF, Enrique. "Complejidad, racionalidad ambiental y diálogo de saberes", In, I Congreso Internacional Interdisciplinar de Participación, Animación e Intervención Socioeducativa, Conferencia, Barcelona, Centro Nacional de Educación Ambiental, 2006, 2-12 pp.

LEFF, Enrique, “Globalización, racionalidad ambiental y desarrollo sustentable”, México: Siglo XXI, 1994, s/p. Disponível em: http://oraloteca.unimagdalena.edu.co/wpcontent/uploads/2013/03/Globalización-Racionalidad-ambiental-y-desarrollo-sustentable.-

Enrique-Leff.pdf; http://www.uccs.mx/sustentabilidad/, 


\section{Artigo original}

Hegemonia - Revista Eletrônica de Relações Internacionais do Centro Universitário Unieuro ISSN: $1809-1261$

UNIEURO, Brasília, número 20, Janeiro-Junho de 2017, pp. 27-49.

consultado: 12 noviembre 2015.

MONTENEGRO, Leonardo. "Naturaleza y Sociedad. A propósito de la naturaleza de los desastres" In, Cultura y Naturaleza: aproximaciones a propósito del bicentenario de la independencia de Colombia, Bogotá, Jardín Botánico de Bogotá, José Celestino Mutis, mayo, 2011. 324- 335 pp.

SANTAMARÍA, Flor, BOTHERT, Karina, "Relatos de niños y niñas: juegos de palabras que crean y recrean vivencias”, In, Revista Infancias Imágenes, vol.10, num.1, enero-junio, 2011, 66-73 pp.

SHIVA, Vandana, "El mundo en el límite", In, El mundo en el límite: la vida en el capitalismo global, eds. Giddens, A., Hutton, W., Barcelona, Tusquets. 2011, 11 pp.

SOSENSKI, Susana, "Dar casa a las voces infantiles, reflexiones desde la historia", In, Revista Latinoamericana de Ciencias Sociales, Niñezy Juventud, v.14, n.1, Colombia, 2016. 43-52 pp.

SVAMPA, Maristella, "América Latina: Consenso de Commodities y lenguajes de valoración en América Latina”, In, Revista Nueva Sociedad, n.244, marzo-abril 2013, 30-46 pp. 